\title{
The Modeling of the Acoustic Condition of Urban Environment Using Noise Annoyance Assessment
}

\author{
Waldemar Paszkowski ${ }^{1}$ (D) $\cdot$ Marcin Sobiech ${ }^{2}$
}

Received: 11 May 2018 / Accepted: 8 October 2018 / Published online: 1 November 2018

(C) The Author(s) 2018

\begin{abstract}
In the following article, a method of modeling urban environment exposed to road noise pollution for the purpose of noise nuisance assessment has been proposed. In order to accomplish it, GIS technology has been applied to divide the area under study into hexagonal fields. The presented case shows an area of urban environment exposed to noise pollution by means of object feature mapping, in each of the adopted elements. An acoustic and non-acoustic analysis of spatial distribution of the researched object features with the application of the adopted assessment indicators has been conducted. In particular, as assessment indicators, the following have been used: landscape entropy $(H), L_{\text {Aeq }}$ (noise_sr), Simpson's diversity index (SIDI), area and length of transportation network $\left(R_{\mathrm{a}}, R_{1}\right)$, buildings (GSI) and number of stories (FSI), predominance of land cover (LIPI), equality of class distribution (SIEI), and geodiversity index $\left(G_{\mathrm{d}}\right)$. The statistical analysis of the validity of the aforementioned indices has also been carried out. For the purpose of noise annoyance assessment modeling, the application of statistically relevant assessment indicators has been proposed with the special use of the neural network method.
\end{abstract}

Keywords Urban environment $\cdot$ Noise annoyance $\cdot$ Sound features $\cdot$ Neural network

\section{Introduction}

The problem of noise pollution in urban environment is particularly troublesome in the place of residence. The subjective aspect of sound perception, as well as changeability of multiple factors which accompany the process of perception, causes that no universal model for noise annoyance assessment has hitherto been developed [1-3]. The commonly used approach to the noise pollution assessment in the place of residence is limited to determining the quantitative indicator by means of reflective modeling and mapping: environment sites as well as distribution of the sound level [4]. For example, [5] features of objects occurring in the environment can be considered from

Waldemar Paszkowski

wpaszkowski@polsl.pl

Marcin Sobiech

marcin.sobiech.map@gmail.com

1 Faculty Organization and Management, Silesian University of Technology, ul. Roosevelta 26-28, 44-800 Zabrze, Poland

2 Faculty of Geology and Hydrogeology, Nicolaus Copernicus University, ul. Lwowska 1, 87-100 Toruń, Poland the point of view of their properties and characteristics [6]. Objects occurring in the urban environment can bear a close resemblance to one another in terms of their features and are typical in terms of repetitiveness of spatial structures. They can be described in terms of the properties and characteristics of the features corresponding to a given surface. In terms of acoustic variables, for the purpose of mapping the properties and characteristics of the features in the set of objects belonging to urban infrastructure, objects of natural origin frequently occur. Sources of noise are treated as objects belonging to the urban environment, whose sound emission and immission parameters are represented by physical acoustic parameters. The research conducted on the objective assessment of the sound perception process in the environment includes not only basic physical parameters such as sound level and its spectrum, but also psychoacoustic features, impulsiveness, duration, and time structure of sound [7]. The aim of the following article is to present a method of modeling traffic noise emergencies in the urban environment by applying selected measures of spatial distribution of object features and noise annoyance assessment. The proposed method can be applied in the tasks concerning supporting the evaluating and forecasting noise pollution in the urban environment, taking particularly into account noise annoyance. 


\section{Description and Presentation of Indicators of Object Feature Assessment from the Acoustic Point of View}

Assessing links between object feature variables and the acoustic parameters of noise sources allows us to create a classification of urban areas in terms of their acoustic criteria. At the same time, the assessment of the impact of noise sources using the frequently applied noise maps technology is based on identifying factors expressed by sound physical measurements, i.e., $L_{\mathrm{Aeq}}, L_{\mathrm{DWN}}, L_{\mathrm{N}}, L_{\mathrm{den}}, L_{\text {night }}[4,8]$. On the one hand, this approach causes certain limitation in assessing noise pollution hazard only to physical features of sound, whereas on the other hand, it overlooks the meaning and significance of the psychoacoustic aspects of noise, including noise annoyance. Research conducted in this area is justified by applying advanced modeling methods in evaluating the environment endangered by noise [9]. It is assumed that the solutions applied will be based not only on taking into consideration physical parameters of acoustic signal assessment, but also on the evaluation of spatial distribution of selected measurements of objects in the urban environment.

\section{Description of Selected Methods of Spatial Analysis}

Digital accessibility to data sets of spatial objects as well as the possibility of using tools supporting spatial information management enables us to effectively perform the most sophisticated tasks ranging from the environmental hazard assessment to noise management. The results of research conducted in this area indicate that urban morphology has a considerable impact on noise distribution level. The research includes dependencies between urban landscape morphology, represented by a specific pattern of land development and streets, and spatial distribution in the urban environment $[9,10]$. In large urban areas, work is being undertaken concerning the assessment of the correlation between huge emitters of acoustic energy, for example, airports and approach airways to runways, and urban areas directly affected by them [11, 12]. Within the framework of the applied methods of assessing and forecasting road traffic noise exposure in residential areas, statistical models are used [13] determining the correlation between spatial distribution of noise level and building geometry and the position of their facades in relation to the emitter [14]. With reference to the urban area or the whole city, research on the assessment of the correlation between the type of land use and noise level distribution as a method of decisionmaking process optimization concerning spatial planning tasks is carried out $[6,15]$. The crucial role of urban green areas as zones reducing the negative impact of road traffic noise is also indicated [16].

\section{Description of the Obtained Data and Information Concerning Object Features}

Urban environment considerably differs from natural landscape. Obtaining a current and spatially continuous information concerning land use in the urban areas is particularly vital in the context of the acoustic assessment of urban environment. Regarding the purpose of the research, data at scale of $1 / 10000$ or greater are crucial in terms of suitability and spatial resolution (level of accuracy).

Researchers carrying out their studies on the territory of Poland take advantage of an updated body of relevant data, i.e., the Topographic Database (BDOT10k) with the accuracy of topographic information at scale of $1 / 10000$. The data collected in the Topographic Database can provide a source of information about basic topographic data concerning the use of spatial information systems. BDOT10k constitutes a certain model of geographical space which stands for selected natural landmarks as well as social and cultural facilities [12]. The database contains information about the physical features of the terrain, but not the type of specific land use or its legal status.

For the purpose of this article, the Topographic Database (BDOT10k) has been obtained from the Central Surveying and Cartographic Documentation Centre (CODGiK) in the shapefile format. This database does not constitute a complete source of information and has been supplemented by detailed information on surface topography (light detection and ranging (LiDAR)) as well as by the data describing land use. Detailed information concerning land cover and surface topography constitutes the data obtained by means of airborne laser scanning from the Central Surveying and Cartographic Documentation Centre (CODGiK). This database constitutes a current and standardized source of information from which three types of land cover have been identified. Within the research carried out, the data concerning land cover coming from BDOT10k and LiDAR have been processed. The types of land cover have been assigned to eight thematic classes (Table 1), which will undergo the process of modeling. The adopted division of land cover into classes, as presented in the Table 1 below, is universal for the entire area of the country. The high resolution of the source data of at least $1 \times 1 \mathrm{~m}$ enables an accurate representation of the actual land cover.

\section{Model of Object Feature Representation}

The urban area under consideration covers the area of $1 \times$ $1 \mathrm{~km}$ and it is situated in the Upper Silesian urban area, within the administrative borders of Świetochłowice. Within the area under study, the terrain exposed to road traffic noise has been designated (Fig. 1). Within the area under examination, a grid of adjacent primary fields, i.e., hexagons of the area of $400 \mathrm{~m}^{2}$ 
Table 1 The adopted division of land cover into classes

\begin{tabular}{ll}
\hline Class & Type of land cover \\
\hline C1 & Ground \\
C2 & Buildings and technical constructions \\
C3 & Roads \\
C4 & Low vegetation \\
C5 & Surface waters \\
C6 & Squares and parking parks \\
C7 & High vegetation \\
C8 & Medium vegetation \\
\hline
\end{tabular}

comprising 2558 elements in total, has been generated. It has been assumed that the area of primary fields of the elements corresponds to the area of rectangular fields of the grid applied in acoustic mapping methodology [8]. In the study of assessing the diversification of spatial structures of different phenomena, when there is no possibility of referring the obtained results to natural units, geometric reference fields (for example, squares, equilateral triangles, or regular hexagons) are applied. In this case study, it has been decided to apply hexagons, from which the grid covering the whole area under consideration has been formed. With such a choice of the geometric field, a greater number of edges adjacent with the neighboring fields enable us to perform more accurate analyses of relations and dependencies between particular fields of assessment than in the case of two remaining types of fields.

Basing on the participation of particular types of land cover in every field of assessment, spatial distribution of

Fig. 1 The model of land cover of the studied area along with the adopted grid of assessment fields
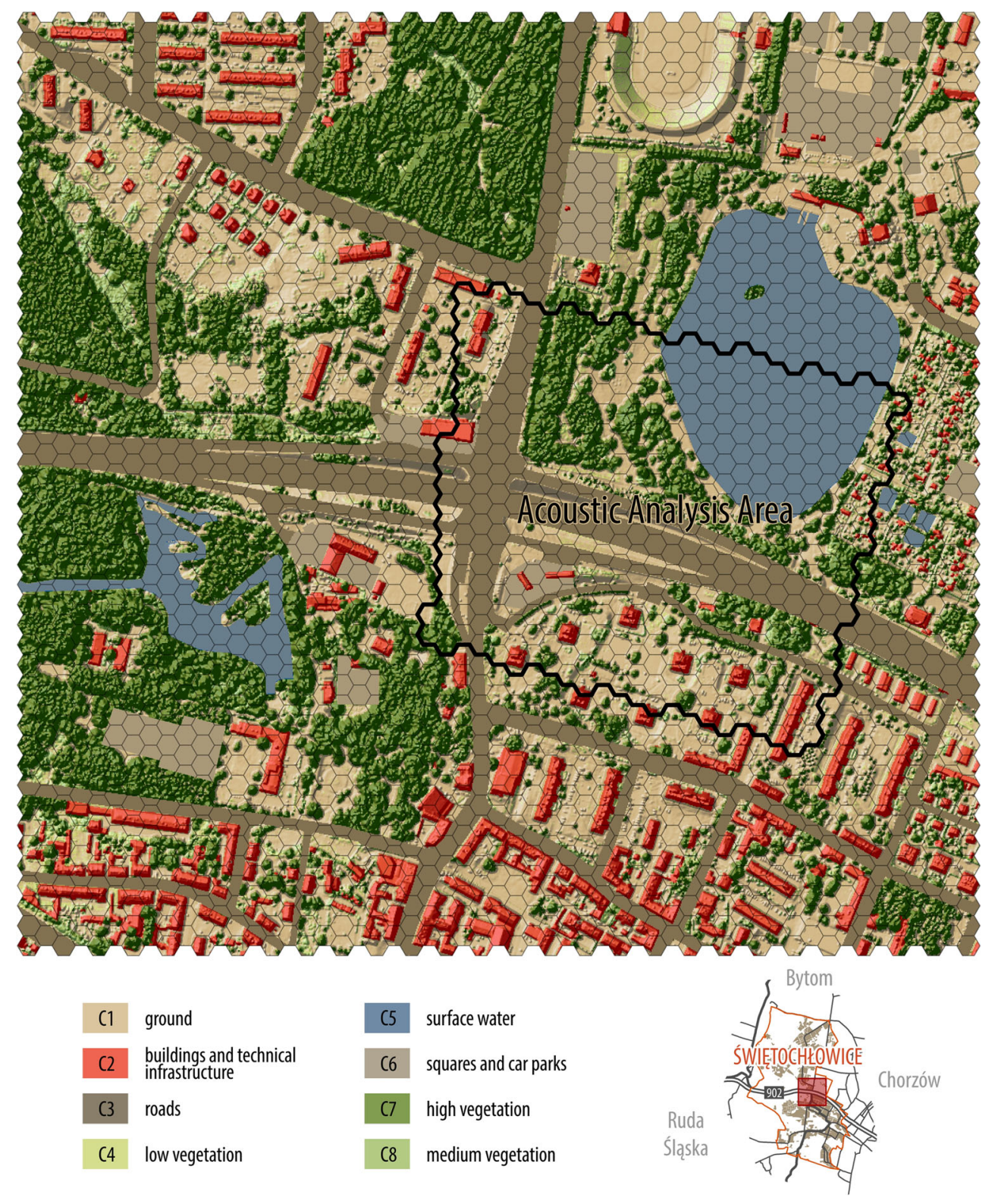
measurement values, which is presented in the subsequent part of the article, has been calculated. Depending on the necessity, data implemented in terms of absolute value, i.e., area or as percentage in relation to the entire area of the assessment field, have been used.

Characteristic elements of land use in the studied area are compact tree strips, building complexes separated by communication routes of Intercity Road Network (DW 902) as well as water reservoirs. The process of modeling features of the urban environment is characterized by certain specificity resulting from the necessity of taking into consideration a third dimension. The information concerning the height of objects has been extracted from the LiDAR data for the purpose of determining the actual height of buildings and technical constructions. Buildings take priority in the context of acoustic research into urban fabric in terms of people's presence or residence in them. The verification of these values has been based on the results of airborne laser scanning and light detection and ranging (LiDAR), with the average height error contained within the range of $0.2 \mathrm{~m}$. On the basis of the class code, it was possible to determine the type of surfaces registered by the sensors of the scanner. Relying on the laser scanning data, we succeeded in dividing vegetation into high vegetation of the height above $2 \mathrm{~m}$ and medium and low vegetation.

A vital piece of information is the identification of the type of material which was used to build walls of specific buildings due to their sound reflecting and sound absorbing properties. This information is not directly available in any commonly accessible databases or sets of data. A source of data can be found in advanced methods of reflection intensity assessment

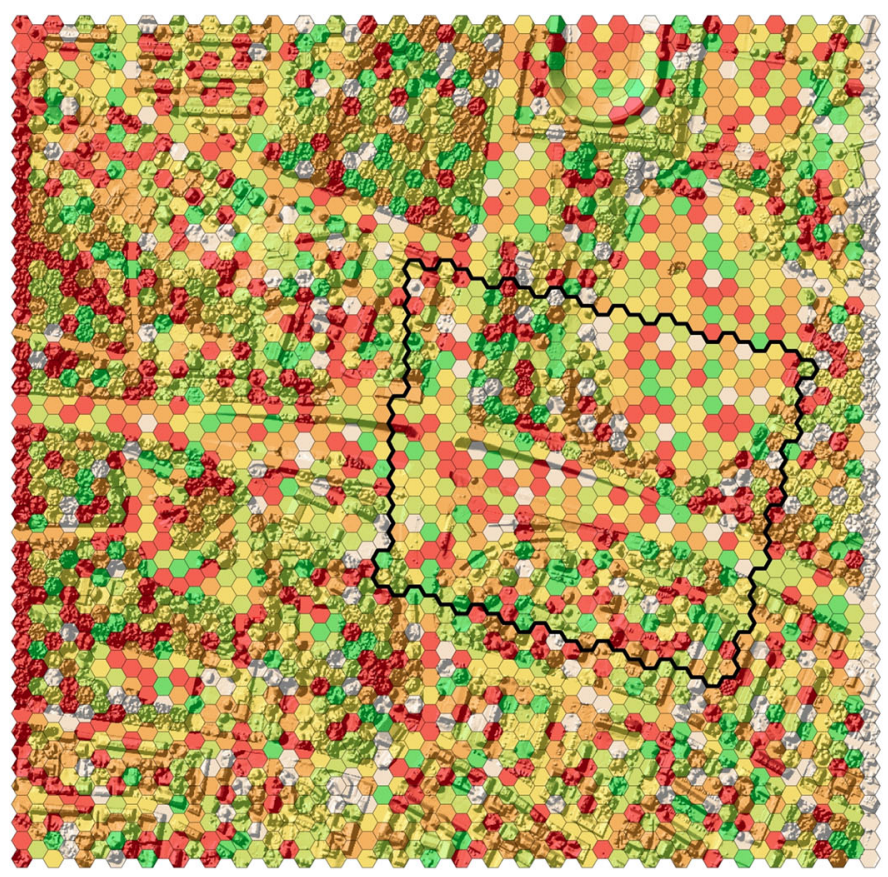

Fig. 2 Spatial distribution of unit entropy $(H)$ in three regions of visible portions of electromagnetic radiation (RGB values) obtained from aerial photographs. In this study, current aerial photographs and street views (accessible from the Google Maps service) as well as diagonal images have been used.

\section{Description and Analysis of Environment Assessment Indicators}

The acoustic assessment of the research field has been carried out taking into account the recommended indicators including diverse features of environment objects. It has been accepted that specific indicators will make allowances for spatial distribution assessment of selected environment features and relations occurring between them. The features under study have been divided into five classes by means of the quantile method [17]. The technique of mapping object features allows performing the spatial distribution assessment of the applied indicators. Every class has been described in terms of quantitative value, where the number 1 has been ascribed to the lowest and number 5 to the highest class. The total number of points from a particular parameter in every field of assessment has been used to create a resulting map of urban environment diversification.

\section{Landscape Entropy $(H)$}

Unit entropy enables the assessment of the degree of heterogeneity of fields. An indicator applied determines the

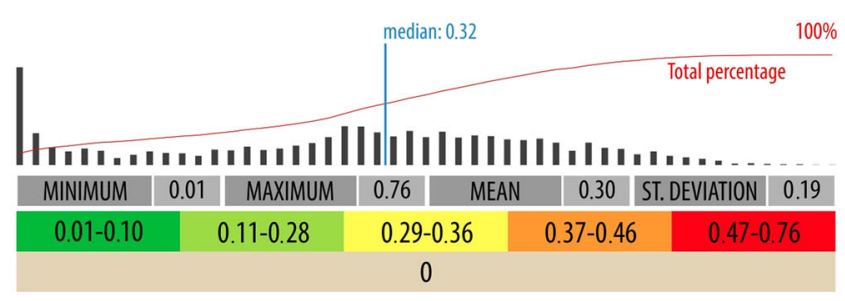


likelihood of object class occurrence in the field of assessment. Shannon's diversity factor depicts the degree of surface feature diversification resulting from the information theory [18]. Landscape entropy assumes the rise in value in relation to the degree of even coverage of the researched area with different land cover classes (Fig. 2). An indicator responds to the occurrence of partial divisions of a small number of elements $[19,20]$.

\section{Simpson's Diversity Index (SIDI)}

Simpson's diversity index determines the likelihood of occurring two partial divisions of the same type within one assessment field. In the case of the indicator's value reaching zero, the diversity is regarded as infinite, whereas if the value equals 1 , no diversity is observed (Fig. 3).

\section{Area and Length of Transportation Network $\left(R_{\mathrm{a}}, R_{\mathrm{l}}\right)$}

The $R_{\mathrm{a}}$ and $R_{\mathrm{l}}$ indicators refer to the assessment of transportation network occurrence in the urban environment. In the case of $R_{\mathrm{a}}$ measure, the area covered with passageways in relation to the entire area of the assessment field is taken into consideration. In the case of the $R_{1}$, the length of the road axis within every assessment field is analyzed [13]. In the case of $R_{\mathrm{a}}$, values approaching " 1 " indicate the entire occupation of the assessment field by the street or road surface. In the case of $R_{1}$,

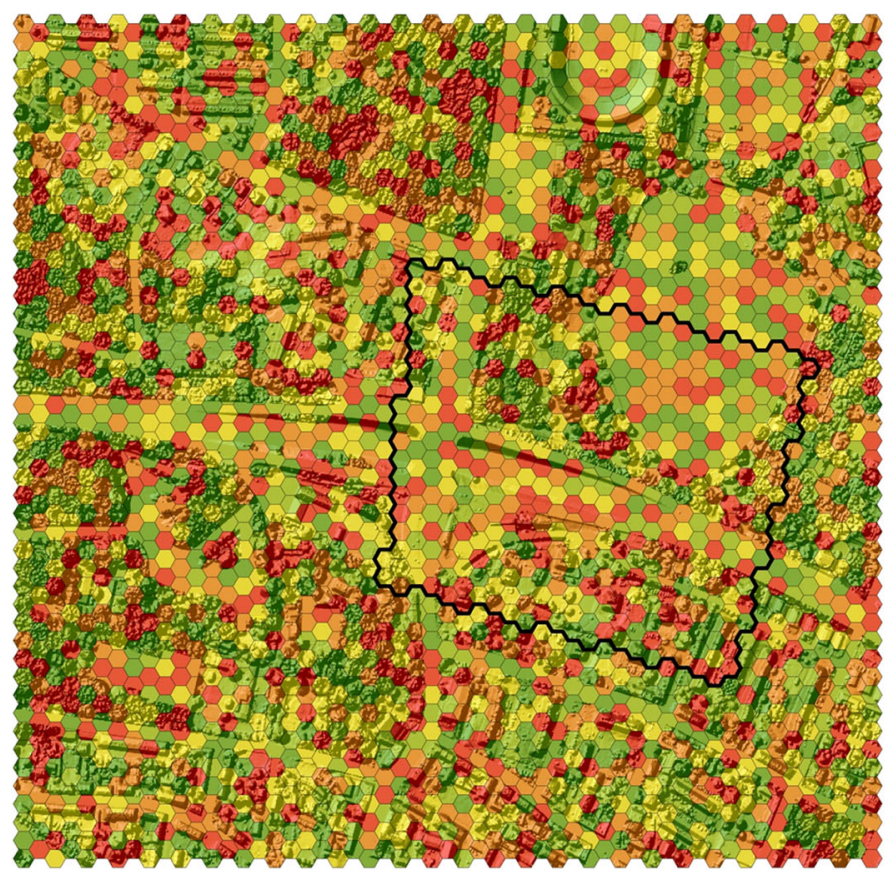

Fig. 3 Spatial distribution of SIDI the indicator values determine the participation of the length of the transportation network expressed in kilometers (Fig. 4).

\section{Buildings (GSI) and Number of Stories (FSI)}

The GSI and FSI indicators refer to building occurring in the area under study (Fig. 5). The GSI is described as the horizontal projection area of the buildings occurring in the assessment field in relation to the entire surface of the area. In the case of the FSI, the stories of the buildings are additionally taken into account, the total of the areas of which is referred to the entire area of the assessment [13].

\section{Predominance of Land Cover (LIPI)}

The LIPI indicator describes the participation of one of the land cover classes characterized by the largest area in relation to the assessment field area. The spatial distribution of the LIPI indicates its highest values in the area under study within homogenous wooded areas and water surfaces (Fig. 6).

\section{Equality of Class Distribution (SIEI)}

The SIEI indicator depicts the degree of equal participation of particular classes of land cover within the assessment field. When the value of the parameter is approximate to zero, the

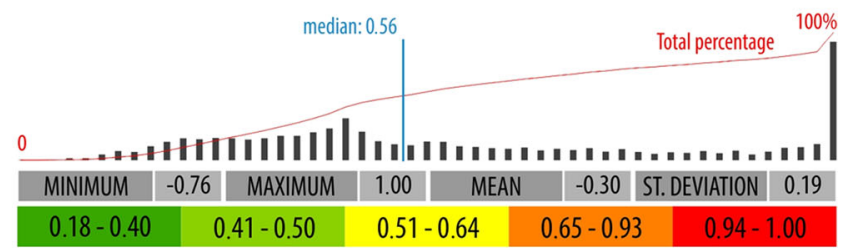




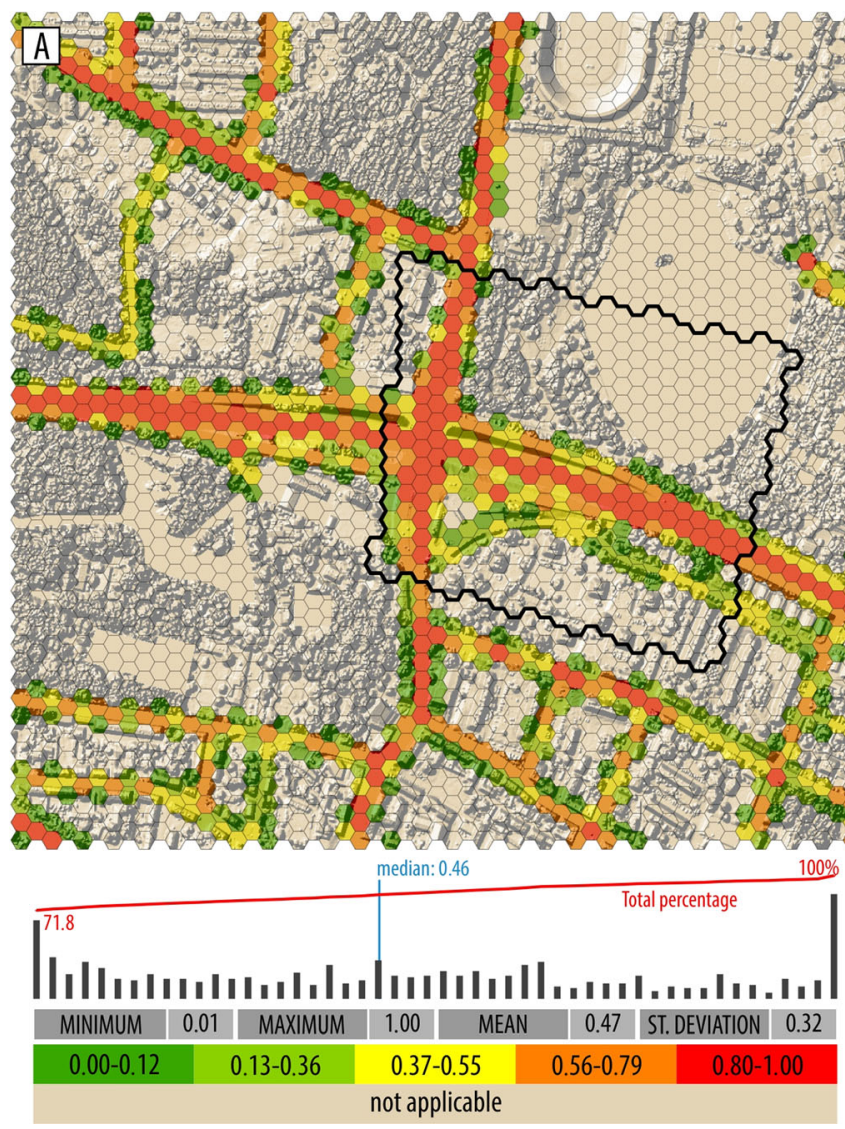

Fig. 4 Spatial distribution of the $R_{\mathrm{a}}(\mathbf{a})$ and $R_{1}(\mathbf{b})$

predominance of one of the classes is observed. In the case of the value coming closer to one, the participation of particular types is balanced (Fig. 7, Table 2).

\section{Noise_sr Indicator}

According to the existing directive [4] in the long-term assessment of the environment exposed to noise pollution, physical parameters of noise assessment, i.e., $L_{\mathrm{DWN}}$ and $L_{\mathrm{N}}$ long-term indicators are applied. A simulated distribution of the values of the $\mathrm{L}_{\mathrm{DWN}}$ and $\mathrm{L}_{\mathrm{N}}$ indicators has been obtained owing to the methodology of acoustic mapping and Cadna A software [21]. The input data for the simulation of noise indicator distribution constituted the values of high intensity of vehicle traffic during $1 \mathrm{~h}$ for daytime. For the purpose of acoustic map calibration, environmental acoustic measurements of the $L_{\mathrm{Aeq}}$ indicator using the SVAN $971 \mathrm{~m}$ have been carried out in three representative reference points, corresponding in time to the measurements of the intensity of vehicle traffic. The information concerning the distribution of the $L_{\mathrm{Aeg}}$ indicator has been converted in the raster form into a snapshot. On the basis of the obtained values, the average value of the $L_{\mathrm{Aeq}}$

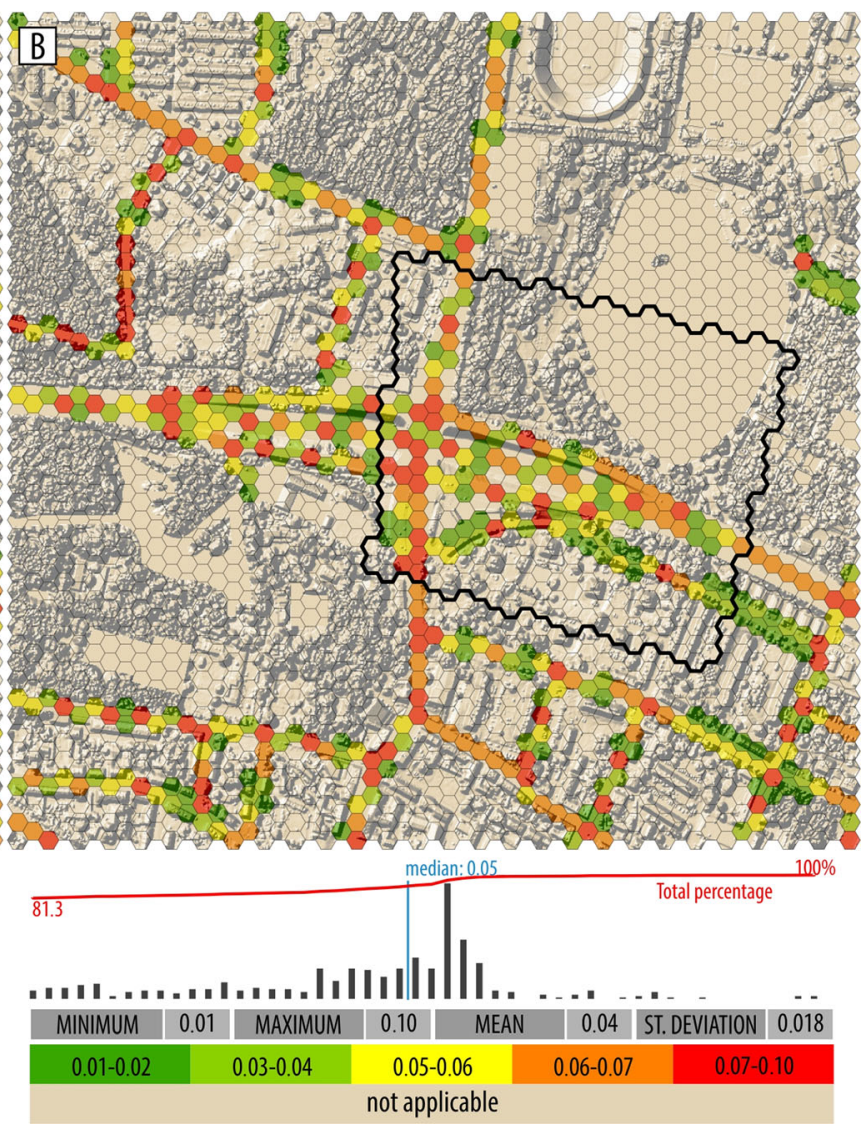

(noise sr) indicator has been determined for every assessment field. Figure 8 presents the spatial distribution of the average value of the $L_{\mathrm{Aeq}}$ indicator.

\section{Assessment of the Environment Exposed to Noise Pollution Using the Geodiversity Index $\left(G_{d}\right)$}

For the purpose of determining an overall assessment of the urban environment in the area under study taking into consideration partial marks of the analyzed measures, the geodiversity index has been proposed (Fig. 9). A theoretical field with the highest geodiversity can receive 40 points, whereas with the lowest geodiversity 0 points. None of the assessment fields has received extreme values and the total of values has ranged from the lowest value of 7 points to the highest value of 32 points.

$E_{\mathrm{g}}$ - the number of environmental elements in the basic field,

$R$-roughness (scabrousness) coefficient in the basic field,

$S$ - the area of the basic field $\left(\mathrm{km}^{2}\right)$. 

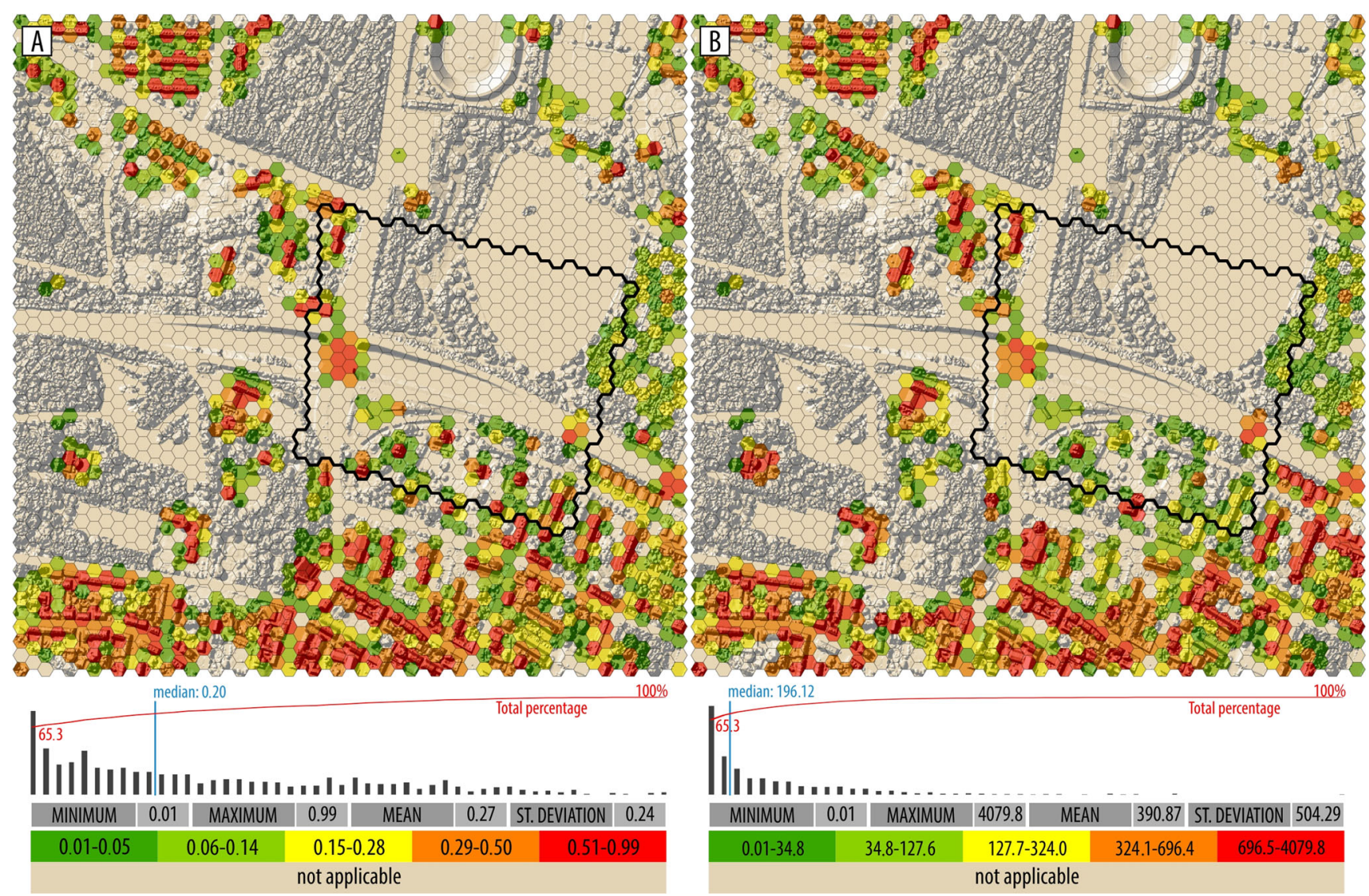

Fig. 5 Spatial distribution of the GSI (a) and the FSI (b)
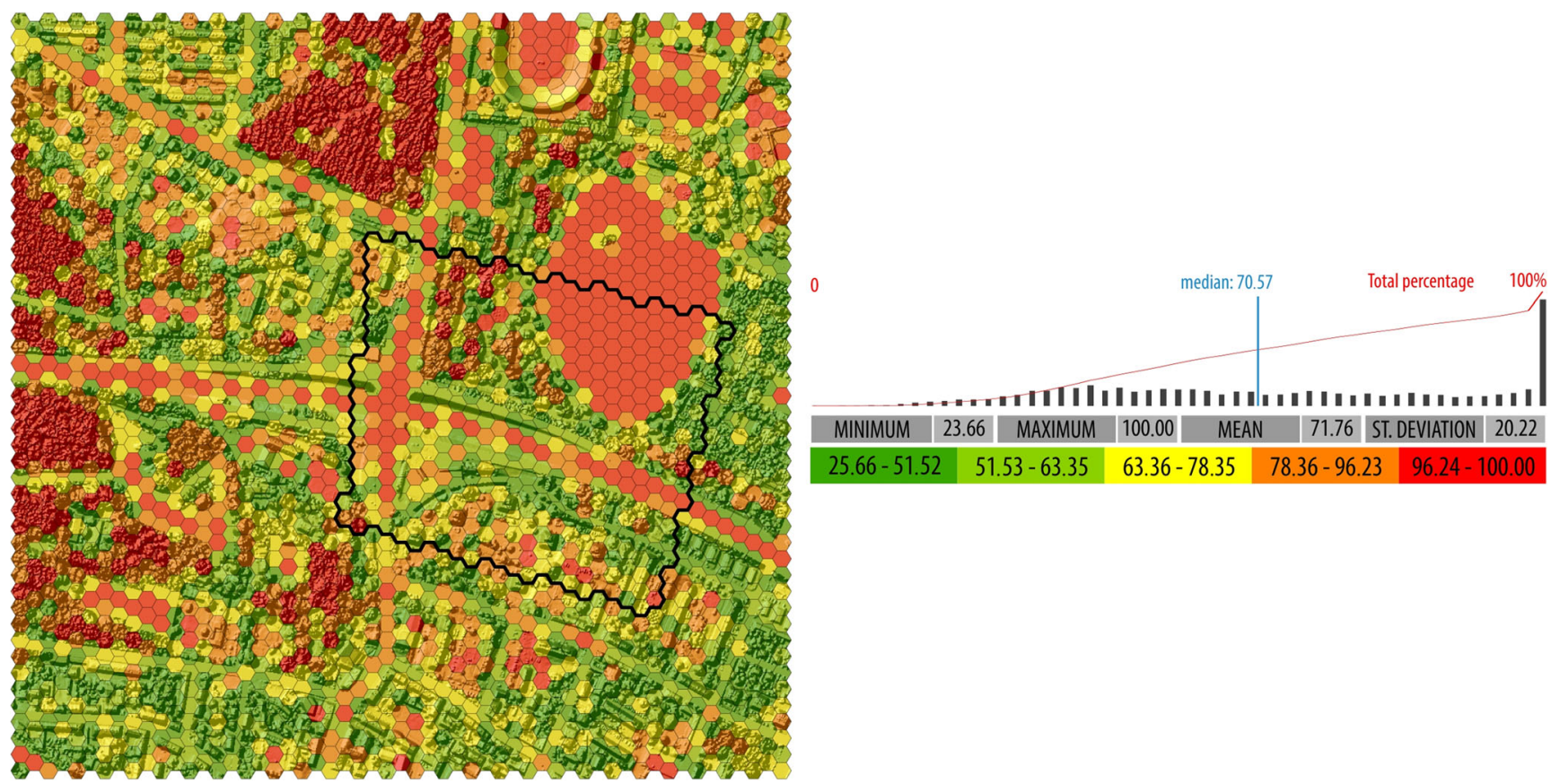

\begin{tabular}{|l|r|r|r|r|}
\hline $25.66-51.52$ & $51.53-63.35$ & $63.36-78.35$ & $78.36-96.23$ & $96.24-100.00$ \\
\hline
\end{tabular}

Fig. 6 Spatial distribution of the LIPI 

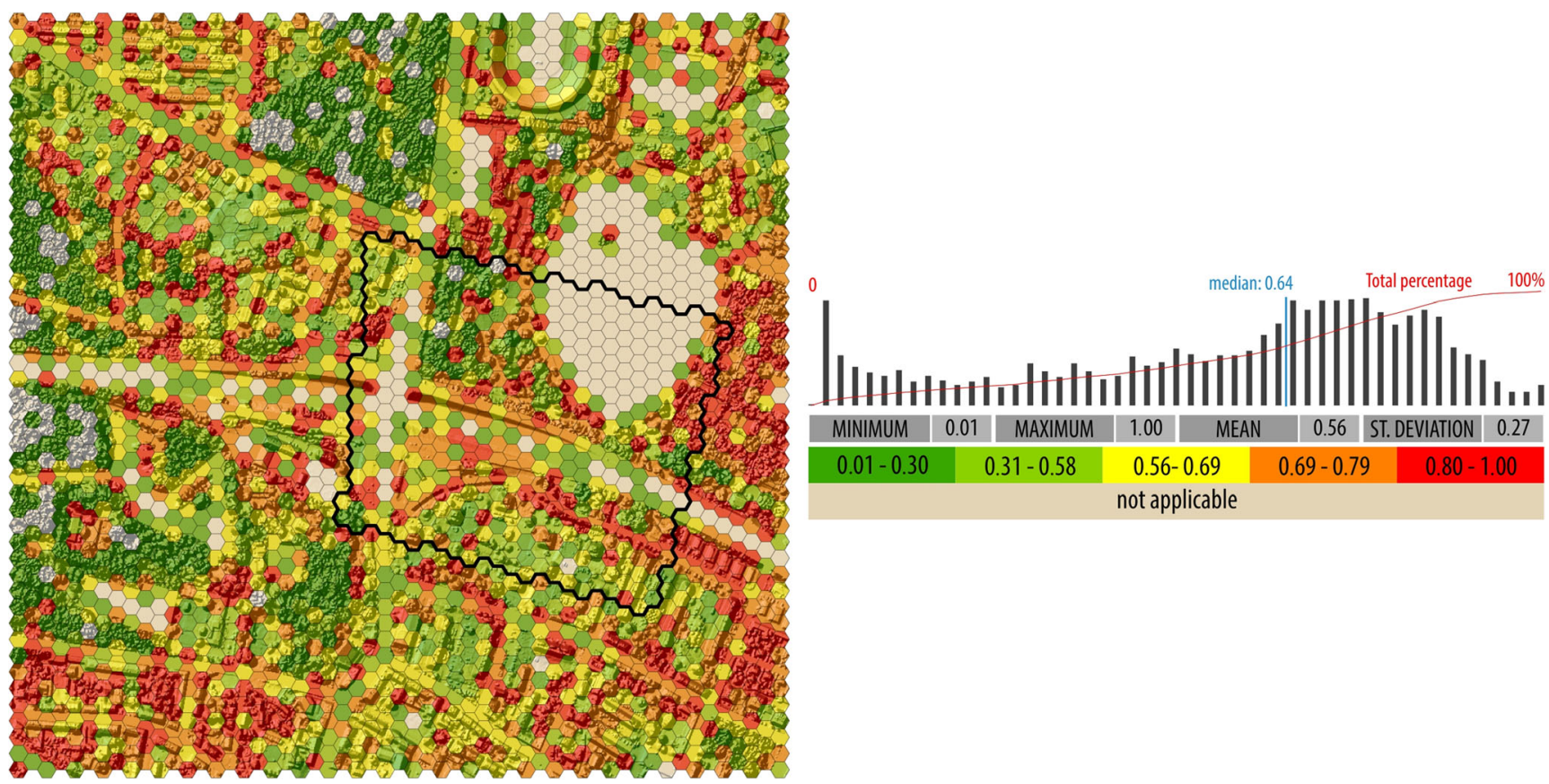

Fig. 7 Spatial distribution of the SIEI

\section{Statistical Evaluation of the Analyzed Indicators}

The applied indicators of assessment have undergone a statistical analysis of relevance for the purpose of constructing an acoustic model of the environment. For this purpose a correlation analysis has been conducted. As a criterion for the input of the independent variable, the value of the index has been adopted. In the model, an additional variable has been taken into consideration, as a distance between the road axis and the midpoint of a field with a building. According to the adopted criterion, four variables have been selected for the construction of the assessment model, i.e., noise_sr, $H ; R_{1}, R_{\mathrm{a}}$. The correlation values of the statistically significant variables, if the condition $(p<0.05)$ is maintained, are presented in Table 3.

Table 2 Description of applied indicators of feature occurrence assessment [19]

\begin{tabular}{|c|c|c|}
\hline Number & Indicator & Formula \\
\hline 1. & $H$ & $\begin{array}{l}H(X)=\sum_{i=1}^{n} p\left(x_{i}\right) \log _{r} \frac{1}{p\left(x_{i}\right)}=-\sum_{i=1}^{n} p\left(x_{i}\right) \log _{r} p\left(x_{i}\right) \\
\text { where } p\left(x_{i}\right) \text { - probability of event occurrence, } r \text { - the base of the logarithm }\end{array}$ \\
\hline 2. & SIDI & $\begin{array}{l}S I D I=1-\sum_{i=1}^{N} p_{i}^{2} \\
\text { where } P_{i} \text { describes the percentage of landscape units assigned to } i \text { class }\end{array}$ \\
\hline 3. & $R_{\mathrm{a}}$ & $\begin{array}{l}R a=\frac{R}{A}, \\
\text { where } R \text { - area covered with roads, } A \text { - area of the assessment field }\end{array}$ \\
\hline 4. & $R_{1}$ & $\begin{array}{l}R l=\frac{L}{A} \\
\text { where } L \text {-length of road axis, } A \text { - area of the assessment field }\end{array}$ \\
\hline 5. & GSI & $\begin{array}{l}G S I=\frac{P b}{A} \text {, } \\
\text { where } P b \text { - horizontal projection area of the buildings, } A \text { - area of the assessment field }\end{array}$ \\
\hline 6. & FSI & $\begin{array}{l}F S I=\frac{(\mathrm{Pb} 1 \mathrm{k} 1)+(\mathrm{Pb} 2 \mathrm{k} 2)+(\mathrm{Pbnkn})}{A}, \\
\text { where } \mathrm{Pb} \text { - area of horizontal projection of the building, } k \text { - number of stories, } A \text { - area of the assessment field }\end{array}$ \\
\hline 7. & LIPI & $\begin{array}{l}L I P I=\frac{\max _{i j}\left(a_{i j}\right)}{A}(100) \\
\text { where } a_{i j} \text { area of the largest land cover class, } A \text {-area of all land cover classes }\end{array}$ \\
\hline 8. & SIEI & $\begin{array}{l}\text { SIEI }=\frac{1-\sum_{i=1}^{m} P_{i}^{2}}{1-\left(\frac{1}{m}\right)} \\
\text { where } P_{i} \text { percentage occupied by a particular type of land cover, } M-\text { number of land cover types }\end{array}$ \\
\hline
\end{tabular}




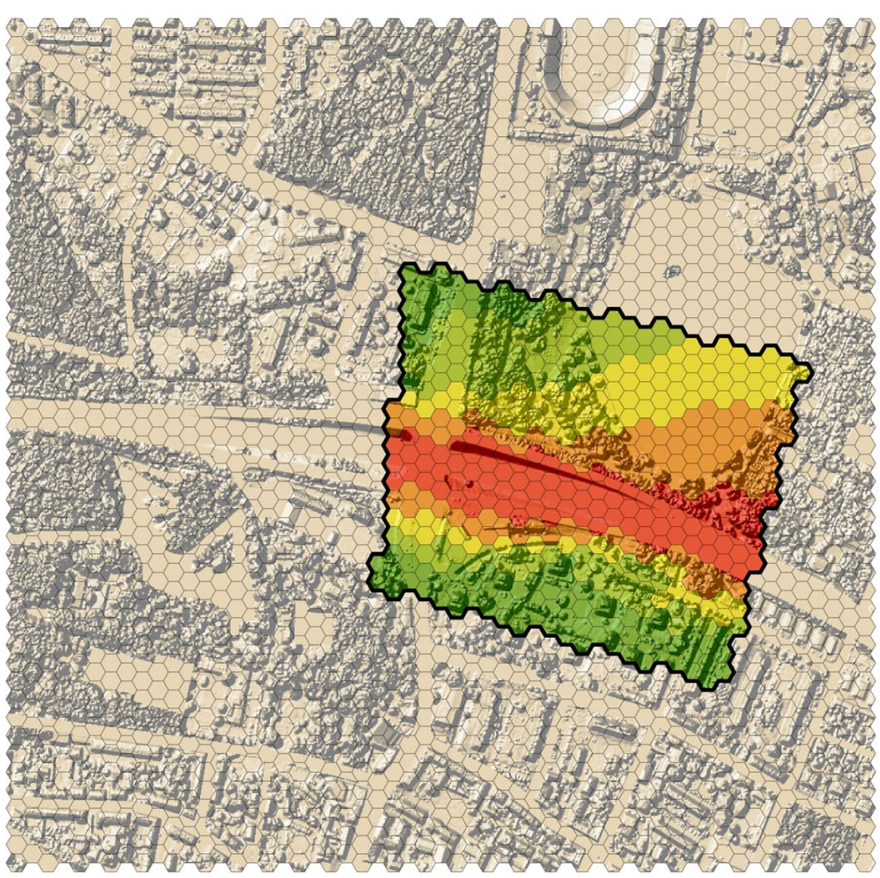

Fig. 8 Spatial distribution of the average value of the $L_{\text {Aeq }}$

The assessment of the analyzed measures for 104 selected hexagonal fields of the researched area, taking into account the $\mathrm{C} 2$ class of object, i.e., buildings has been conducted. On the basis of the index value formulation (Table 4), it can be concluded that with the applied attempt at 104 observations, correlation plays a significant part. Due to the complexity of the research problem and diversity of applied indicators, neural network has been selected as a method of assessment model construction and acoustic environment forecasting.

\section{Modeling of the Acoustic Environment Assessment Using Neural Network}

According to the results obtained from the correlation analysis, the following inputs and outputs have been adopted in the construction of the neural network model:

- four input variables, i.e., noise_sr; $H ; R_{\mathrm{l}}, R_{\mathrm{a}}$,

- one output variable, i.e., the assessment of noise annoyance obtained in laboratory conditions.

As a laboratory experiment, the assessment of noise annoyance and road traffic noise exposure in the studied urban environment has been carried out. During the experiment, acoustic signals of the researched road traffic noise from 30 registered samples were randomly emitted. The stereo signals were emitted from two loudspeakers. The scaling method of assessment for noise annoyance of every single signal was applied in the range from 1 to 5 . The experiment involved the participation of 80 residents aged between 22 and 60 . As a criterion of

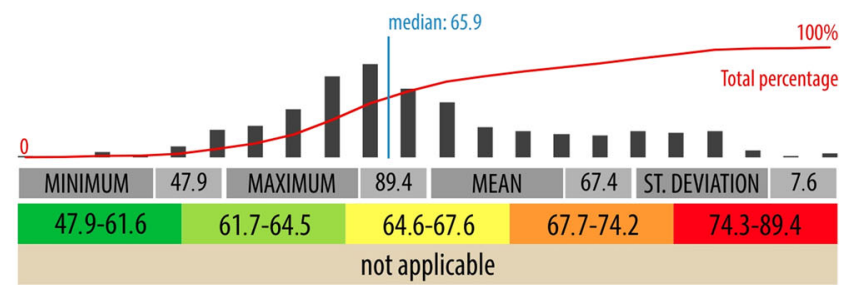

network structure selection, the learning quality and learning error were selected (Fig. 10).

Table 4 contains output values for network learning. The basis for the network selection was the learning quality index, which ranges in value from 0 to 1 .

The obtained model describes the phenomenon under study more accurately if the index value approaches 1 . Root mean square value of the index can be treated as the adjustment measure of theoretical values to empirical values in terms of learning (in our case study $90 \%$ of randomly selected observations). In the hidden network layer, the hyperbolic tangent has been applied as activation function whereas in the output layer activation function has been performed by the linear function (Fig. 11).

In the analyzed case study consisting of 4 input variables, the learning quality has hovered around 0.985 in relation to the learning error at the level of 0.014 -Table 4 . The learning parameter in the Table 4 shows a correlation between theoretical values of the dependent variable (noise annoyance assessment) and values obtained by means of the network. The network error has been calculated as the total of square difference between theoretical and empirical values for $90 \%$ cases of values.

\section{Research Results' Discussion}

The adopted method of acoustic environment assessment in the study takes into consideration the selected indicators including spatial distribution of diverse object features (Table 3). The obtained values of particular assessment 
Fig. 9 Spatial distribution of the geodiversity index in the researched area
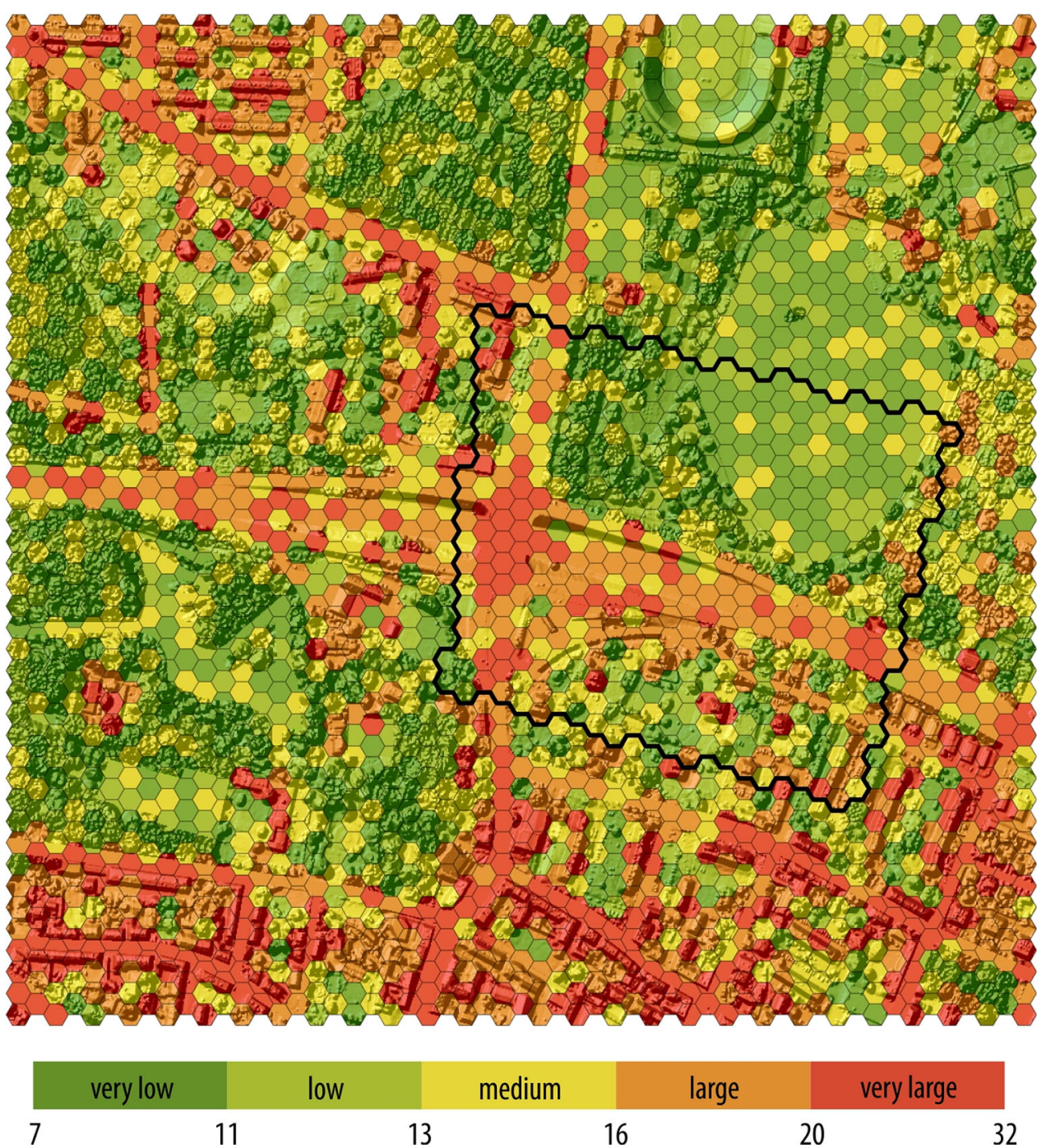

indicators give important information about the environment. The geodiversity index applied in the study takes into account spatial distribution indicator, and therefore, it can constitute the integration of the features of the urban environment. In particular, the highest index values are characteristic for fields

Table 3 Correlation analysis results of the analyzed indicators

\begin{tabular}{lr}
\hline Variable & $r$ \\
\hline$R_{\mathrm{l}}$ & -0.50 \\
$R_{\mathrm{a}}$ & -0.76 \\
noise_sr & -0.95 \\
$H$ & 0.43 \\
LIPI & -0.33 \\
SIDI & 0.05 \\
GSI & -0.21 \\
FSI & -0.27 \\
SIEI & 0.37 \\
$G_{\mathrm{d}}$ & 0.36 \\
\hline
\end{tabular}

located in the vicinity of passageways along with residential areas. The designated correlation factor noise_sr together with the $G_{\mathrm{d}}$ index is at the level of 0.36 . It is assumed that the combination of the $G_{\mathrm{d}}$ index distribution with the noise_sr values will be the subject of further research into the actual acoustic representation of the environment exposed to road traffic noise. The obtained results from the applied neural network model indicate correspondence to the obtained evaluation of noise annoyance from the residents.

Table 4 Selected output values of the applied neural network

Parameters of network output

\begin{tabular}{lcc}
\hline Learning (90\%) & Test (5\%) & Validation (5\%) \\
\hline 0.985303 & 0.572523 & 0.986583 \\
\hline
\end{tabular}


Fig. 10 Model of the applied structure of neural network (own elaboration)
Neural network 4-4-1

Input layer Hidden layer
Output layer

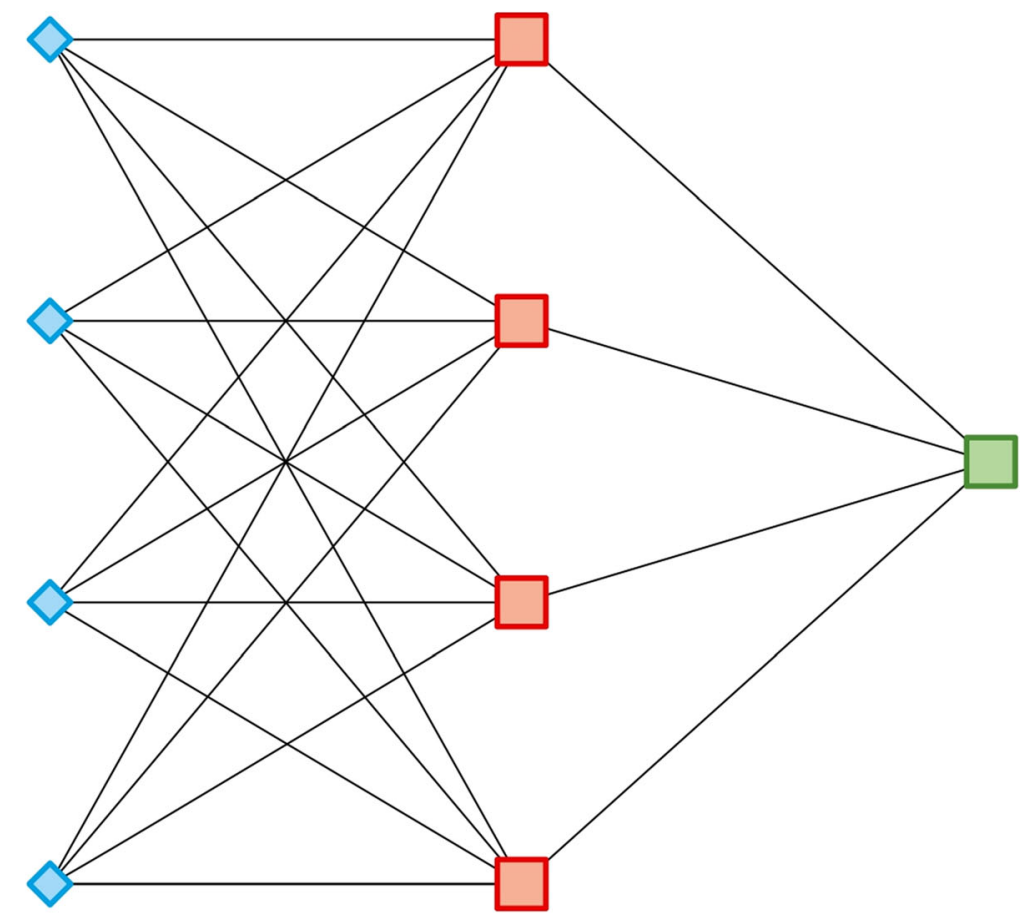

$n=4$

$n=4$

$n=1$

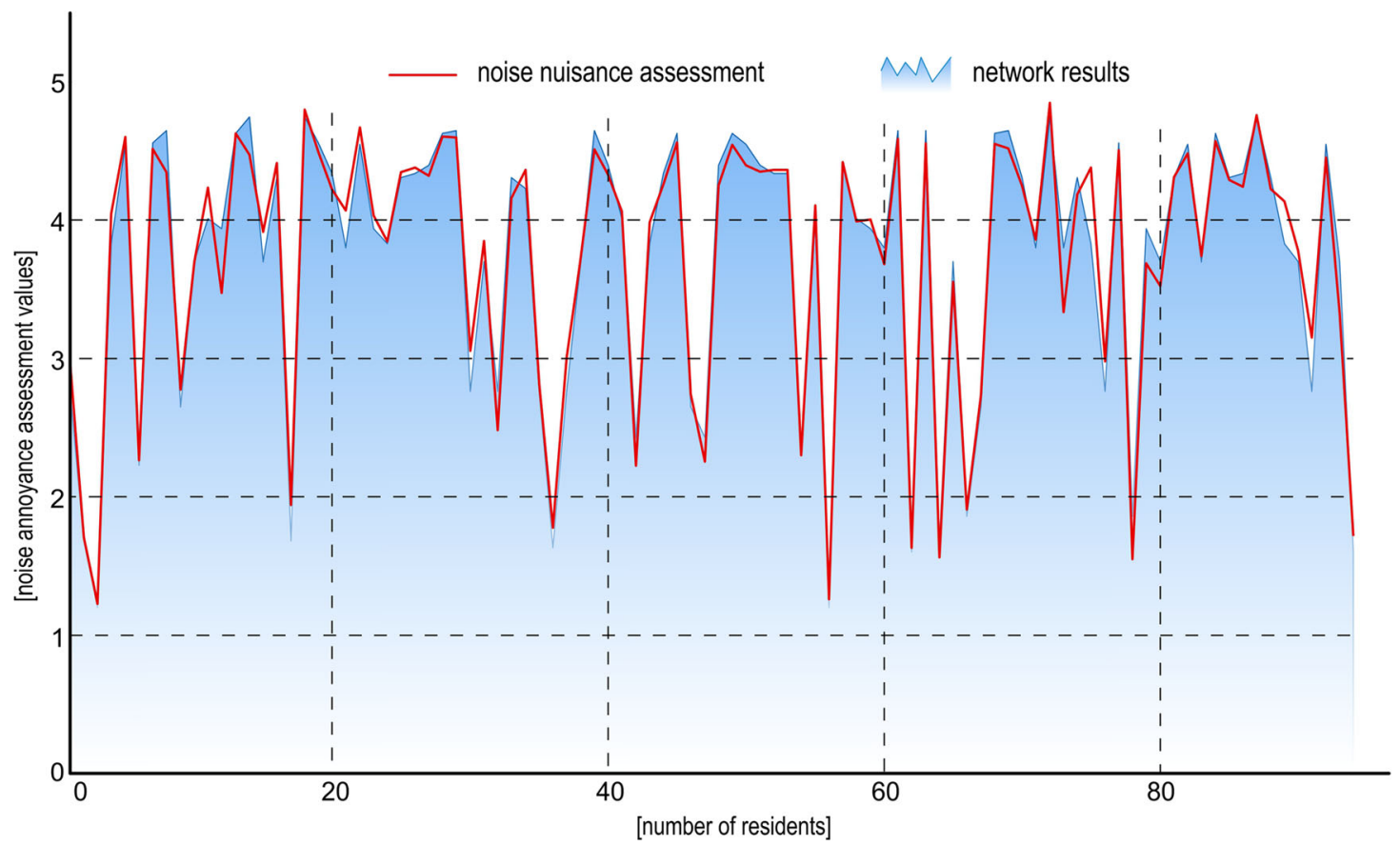

Fig. 11 Juxtaposition of noise annoyance assessment values with network result values (own elaboration) 


\section{Conclusions}

An original approach to acoustic research in the urban environment based on identification, separation, and assessment of object features within the basic (hexagonal) fields of the studied area has been proposed. The presented method of modeling noise annoyance assessment uses information concerning spatial distribution of object features of the environment making allowances for the resident exposure to noise annoyance. Selected indicators of environment spatial assessment have been applied taking into consideration participation and relation of features within and between particular fields in the adopted division network of the studied area.

The application of neural network as a method of modeling noise annoyance assessment has been proposed on the basis the obtained results of spatial distribution of indicators and noise annoyance. Relying on the obtained results of the relevance of the analyzed indicators, it has been concluded that for the model of neural network under analysis, indicators: noise sr; $H ; R_{\mathrm{i}}$, and $R_{\mathrm{a}}$ as well as the noise annoyance assessment will be considered. The proposed method of features modeling along with the adopted model of neural network enables the successful accomplishment of the tasks concerning the assessment and forecasting exposure to noise pollution in the urban environment. One of the advantages of the network model is the possibility of forecasting the acoustic condition of the environment for different variants of feature changeability of environment objects.

Open Access This article is distributed under the terms of the Creative Commons Attribution 4.0 International License (http:// creativecommons.org/licenses/by/4.0/), which permits unrestricted use, distribution, and reproduction in any medium, provided you give appropriate credit to the original author(s) and the source, provide a link to the Creative Commons license, and indicate if changes were made.

\section{References}

1. Paszkowski, W., \& Loska, A. (2017). The use of neural network model in the assessment of annoyance of the industrial noise sources. In A. Burduk \& D. Mazurkiewicz (Eds.), Intelligent systems in production engineering and maintenance-ISPEM. Advances in intelligent systems and computing (Vol. 637, pp. 428-439).

2. W. Paszkowski, A. Loska, (2017). The use of data mining methods for the psychoacoustic assessment of noise in urban environment. Proceedings of 17 th International Multidisciplinary Scientific GeoConference: Ecology, economics, Education and Legislation. Ecology and Environmental Protection, vol. 17, Issue 52, 10591066. https://sgemworld.at/sgemlib/spip.php?article10631\&lang=en
3. Ongel, A. (2016). Inclusion of noise in environmental assessment of road transportation. Environmental Modeling and Assessment, 21, 181-192. https://doi.org/10.1007/s10666-015-9477-z.

4. Directive 2002/49/EC of the European Parliament and of the Council of 25 June 2002 relating to the assessment and management of environmental noise, (2002).

5. W. Paszkowski, M. Dąbrowski, (2017). The use of acoustic maps in modeling features of objects oriented on acoustic quality of the environment. Proceedings of 17th International Multidisciplinary Scientific GeoConference. Informatics, geoinformatics and remote sensing. Cartography and GIS, vol. 17, Issue 23, 769-776. https:// sgemworld.at/sgemlib/spip.php?article9567

6. Xie, D., Liu, Y., \& Chen, J. (2011). Mapping urban environmental noise: a land use regression method. Environmental Science and Technolology, 45, 7358-7364.

7. Fastl, H., \& Zwicker, E. (2007). Psychoacoustics: facts and models (3rd ed.). Berlin: Springer-Verlag.

8. R. Kucharski (red.), (2016). Wytyczne do sporządzania map akustycznych. Wersja znowelizowana, Główny Inspektorat OchronyŚrodowiska, IOŚ-PIB, Warszawa.

9. Bouzir, T. A. K., \& Zemmouri, N. (2017). Effect of urban morphology on road noise distribution. Energy Procedia, 119, 376-385.

10. Wang, B., \& Kang, J. (2011). Effects of urban morphology on the traffic noise distribution through noise mapping: a comparative study between UK and China. Applied Acoustics, 72, 556-568.

11. Flores, R., Gagliardi, P., Sennsio, C., \& Licitra, G. (2017). A case study of the influence of urban morphology on aircraft noise. Australian Acoustical Society, 45, 389-401.

12. Hao, Y., \& Kanf, J. (2014). Influence of mesoscale urban morphology on the spatial noise attenuation of flyover aircrafts. Applied Acoustics, 84, 73-82.

13. Ryu, H., Park, I. K., Chun, B. S., \& Chang, S. I. (2017). Spatial statistical analysis of the effects of urban form indicators on roadtraffic noise exposure of a city in South Korea. Applied Acoustics, $115,93-100$.

14. Salomons, E. S., \& Pont, M. B. (2012). Urban traffic noise and the relation to urban density, form, and traffic elasticity. Landscape and Urban Planning, 108, 2-16.

15. Lin, T., Sun, C., Li, X., Zhao, Q., Zhang, G., Ge, R., Ye, H., Huang, N., \& Yin, K. (2016). Spatial pattern of urban functional landscapes along an urban-ruralgradient: a case study in Xiamen City, China. International Journal of Applied Earth Observation and Geoinformation, 46, 22-30.

16. Sakieh, Y., Jaafari, S., Ahmadi, M., \& Danekar, A. (2017). Green and calm: Modeling the relationships between noise pollution propagation and spatial patterns of urban structures and green covers. Urban Forestry \& Urban Greening, 24, 195-211.

17. Kot, R., \& Sobiech, M. (2013). Ocena georóżnorodności rzeźby terenu wybranych fragmentów krajobrazu młodoglacjalnego Pojezierza Chełmińsko-Dobrzyńskiego. Rocznik Świętokrzyski Seria B - Nauki Przyrodnicze, Tom, 34, 77-92.

18. Shannon, C., \& Weaver, W. (1949). The mathematical theory of communication. Urbana: Univ. Illinois Press.

19. K. McGarigal,S.A. Cushman, E. Ene, (2012). FRAGSTATS v4: spatial pattern analysis program for categorical and continuous maps. Computer software program produced by the authors at the University of Massachusetts, Amherst.

20. Urbański, J. (2012). GIS $w$ badaniach przyrodniczych. Gdańsk: Wydawnictwo Uniwersytetu Gdańskiego.

21. CadnaA software, DataKustik GmbH, (2015). 